\title{
Endoscopic Management of Combined Biliary and Duodenal Obstruction
}

\author{
Zaheer Nabi and D. Nageshwar Reddy \\ Department of Gastroenterology, Asian Institute of Gastroenterology, Hyderabad, India
}

Combined obstruction of the bile duct and duodenum is a common occurrence in periampullary malignancies. The obstruction of gastric outlet or duodenum can follow, occur simultaneously, or precede biliary obstruction. The prognosis in patients with combined obstruction is particularly poor. Therefore, minimally invasive palliation is preferred in these patients to avoid morbidity associated with surgery. Endoscopic palliation is preferred to surgical bypass due to similar efficacy, less morbidity, and shorter hospital stay. The success of endoscopic palliation depends on the type of bilioduodenal stenosis and the presence of previously placed duodenal metal stents. Biliary cannulation is difficult in type II bilioduodenal strictures where the duodenal stenosis is located at the level of the papilla. Consequentially, technical and clinical success is lower in these patients than in those with type I and III bilioduodenal strictures. However, in cases with failure of endoscopic retrograde cholangiopancreatography, with the introduction of endoscopic ultrasound for biliary drainage, the success of endoscopic bilioduodenal bypass is likely to increase further. The safety and efficacy of endoscopic ultrasound-guided drainage has been documented in multiple studies. With the development of dedicated accessories and standardization of drainage techniques, the role of endoscopic ultrasound is likely to expand further in cases with double obstruction. Clin Endosc 2019;52:40-46

Key Words: Endoscopy; Jaundice, obstructive; Gastric outlet obstruction

\section{INTRODUCTION}

Gastric outlet obstruction (GOO) develops commonly in patients with malignant biliary obstruction (MBO) due to periampullary malignancies. About $15 \%-20 \%$ patients with pancreatic cancer will develop GOO. ${ }^{1}$ The occurrence of duodenal obstruction is usually preceded by biliary obstruction in most cases. ${ }^{2,3}$ The options for palliation in these cases include-surgical bypass, endoscopic stenting, and percutaneous biliary drainage in combination with endoscopic enteral

Received: June 11, 2018 Revised: July 1, 2018

Accepted: July 12, 2018

Correspondence: Zaheer Nabi

Department of Gastroenterology, Asian Institute of Gastroenterology, 6-3-661, Somajiguda, Hyderabad 500082, India

Tel: +91-40-2337-8888, Fax: +91-40-2332-4255, E-mail: zaheernabi1978@gmail. com

ORCID: https://orcid.org/0000-0003-2713-4781

cc This is an Open Access article distributed under the terms of the Creative Commons Attribution Non-Commercial License (http://creativecommons.org/ licenses/by-nc/3.0) which permits unrestricted non-commercial use, distribution, and reproduction in any medium, provided the original work is properly cited. stenting. Most of the cases with double obstruction have advanced disease and therefore, are not candidates for surgery. Endoscopic management of bilioduodenal strictures is a minimally invasive option with comparable efficacy to surgery. Endoscopic stenting using self-expandable metal stents (SEMS) has been found to be associated with higher clinical success, a shorter time to oral intake, less morbidity and mortality, lower incidence of delayed gastric emptying, and a shorter hospital stay than surgical gastroenterostomy (GE). ${ }^{4-6}$ In addition, endoscopic stenting is probably more cost effective than open or surgical gastrojejunostomy. ${ }^{7,8}$ When compared to percutaneous drainage, endoscopic biliary drainage is associated with fewer adverse events. ${ }^{9}$

The techniques of endoscopic palliation have evolved over last few decades. Endoscopic palliation of bilioduodenal strictures was synonymous with endoscopic retrograde cholangiopancreatography (ERCP) and enteral stenting till now. The evolution of endoscopic ultrasound (EUS) as a therapeutic modality has boosted the scope of minimally invasive palliation in these cases. EUS-guided biliary drainage (EUS-BD) 
and gastrojejunostomy are likely to play important roles in these patients in the future.

\section{ENDOSCOPIC BILIODUODENAL BYPASS}

\section{Classification of bilioduodenal strictures}

Bilioduodenal strictures have been classified according to the location and relative timing of duodenal obstruction. In type I strictures, duodenal obstruction is located proximal to the papilla. In type II and III bilioduodenal strictures, the location of duodenal obstruction is at or distal to the papilla, respectively. ${ }^{3}$ Bilioduodenal stenosis can also be classified according to the degree of duodenal obstruction and the relative timing of obstruction. In cases with a mild degree of duodenal obstruction, biliary cannulation can be attempted using a slim duodenoscope or after gentle dilatation of the stenosis. On the other hand, duodenal obstruction of a significant degree warrants the placement of an enteral stent first. Biliary obstruction may precede GOO, occur simultaneously, or may follow GOO. These classification systems of bilioduodenal stenosis have therapeutic relevance. Endoscopic management of type I and III bilioduodenal strictures is relatively easy as the papilla is spared. In contrast, the management of type II bilioduodenal strictures may be challenging due to the involvement of the papilla as well as technical problems in getting a good scope position relative to the papilla. For the same reason, technical success is lower with type II strictures than with type I and III strictures. ${ }^{3,10,11}$ Similarly, in cases where GOO precedes biliary obstruction, subsequent biliary cannulation becomes challenging due to an indwelling duodenal stent.

\section{Techniques}

An endoscopic approach to bilioduodenal strictures involves balloon dilatation of the duodenal stricture or enteral stent placement to facilitate biliary cannulation. If unsuccessful, rescue procedures such as percutaneous or EUS-assisted drainage procedures are required. In the following section, we discuss various techniques of endoscopic bilioduodenal bypass.

\section{Biliary stenting first}

The insertion of a biliary metal stent is usually attempted before deployment of a duodenal stent as the latter may impair the visualization of the papilla. In some cases, careful negotiation of the stricture with the duodenoscope is successful. In this scenario, a slimmer ERCP scope may be preferred for easy negotiation across the duodenal stenosis (e.g., JF-260V with distal end of $12.6 \mathrm{~mm}$ ). Alternatively, gentle balloon dilatation using a forward viewing scope can be performed and duodenal intubation re-attempted. ${ }^{12-14}$ The technique of negotiating the duodenal stenosis after balloon dilatation is as follows. In the push technique, the balloon is closely approximated to the scope after dilatation and pushed across the stricture as a single unit. ${ }^{12,13}$ If unsuccessful, the hooking method can be used as described by Kikuyama et al. ${ }^{15}$ In this technique, the duodenal stenosis is initially dilated using a large balloon. Subsequently, the balloon is deflated, pushed beyond the stricture, and re-inflated. Finally, the balloon is pulled towards the scope and used as an anchor to straighten and advance the scope towards the papilla. ${ }^{15}$

The above-mentioned techniques have been successfully utilized in several studies. ${ }^{12,13,15}$ However, it is important to note that unlike benign enteral stenosis, malignant strictures are friable and dilatation is not risk free. In addition, bleeding after dilatation may hamper the visualization of the papilla and reduce the chances of successful biliary cannulation.

Alternative techniques for biliary drainage (like EUS-guided or percutaneous) should be promptly considered if more than a slight resistance is encountered while negotiating duodenal stenosis.

\section{Duodenal stenting first}

In cases with tight duodenal stenosis and failure of the above mentioned strategies, temporary placement of covered enteral metal stents can be used successfully. ${ }^{16,17}$ In one study, temporary placement of covered metal stents was used after failed ERCP due to duodenal stenosis. ${ }^{17}$ Most of these had periampullary malignancies. All the stents were successfully removed after one week. Subsequently, ERCP was successful in about three-fourth of the cases. ${ }^{17}$ Although attractive, such an approach has not been evaluated in additional studies. Moreover, covered stents are prone to migration and another duodenal SEMS would be ultimately required subsequent to the biliary stenting, adding to the overall cost of the procedure. $^{16}$

A more reasonable approach in cases with concurrent bilioduodenal stenosis is to deploy an uncovered enteral stent first. Thereafter, ERCP can be attempted in the same session. If unsuccessful, ERCP can be successfully re-attempted after 48-72 hours as it gives sufficient time for the enteral stent to expand maximally (Fig. 1).

In cases with type I (proximal to the papilla) and III (distal to the papilla) bilioduodenal strictures, care is taken to avoid covering the papillary opening with the duodenal stent. In cases with type II strictures, the biliary stent is placed through the mesh of the previously placed enteral stent. The manipulation of the scope and accessories is difficult in these cases. Moreover, identification of the biliary opening and successful cannulation is challenging. These factors explain the relatively 


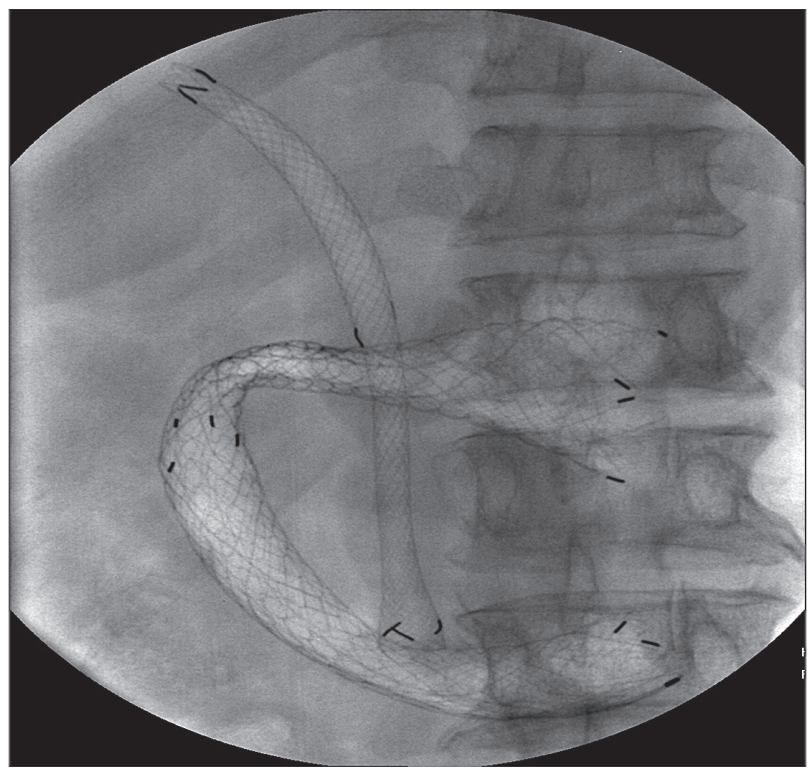

Fig. 1. Fluoroscopic image revealing successful placement of biliary and duodenal metal stents in a patient with type I bilioduodenal stenosis.

lower success of ERCP in type II bilioduodenal stenosis. In order to facilitate the placement of a biliary stent, the mesh of an enteral stent can be widened using a balloon, rat tooth forceps, or argon plasma coagulation. ${ }^{3,18}$ Alternatively, specially designed enteral stents can be used. These stents have a crosswired and unfixed structure in the central $3 \mathrm{~cm}$ or lateral portion. ${ }^{19}$ These features allow easy insertion of biliary metal stents through the mesh of the duodenal stent. However, there has been no study so far comparing traditional enteral stents to these specially designed metal stents in cases with combined obstructions.

\section{Rescue procedures}

The most important factor in determining successful outcomes is the type of bilioduodenal stenosis i.e. type II vs. type I and III. Other factors that may predict the failure of ERCP biliary metallic stenting include the length of the malignant duodenal stricture $(>3.5 \mathrm{~cm})$ and longer duodenal stents $(80-90 \mathrm{~mm}){ }^{20}$ Percutaneous and EUS-guided rendezvous procedures can be performed in these cases. In expert centers, EUS-BD is preferred over percutaneous drainage due to similar efficacy and reduced morbidity associated with the former. ${ }^{21,22}$ In a multicenter randomized trial, the rates of procedure-related adverse events (8.8\% vs. $31.2 \%$ ) and unplanned re-interventions were significantly higher in the percutaneous biliary drainage group than in the EUS-BD group. ${ }^{21}$

\section{Outcomes of endoscopic bilioduodenal bypass}

Endoscopic management of combined bilioduodenal strictures is successful in $34 \%-100 \%$ of cases (Table 1 ). ${ }^{2,3,10,12-14,19,23-25}$
After endoscopic drainage, re-intervention may be required in about a quarter of patients. The outcomes of endoscopic drainage not only depend on the type of strictures, but also the relative timings of biliary and duodenal strictures. If biliary obstruction occurs first and a metal stent has already been placed, subsequent placement of an enteral stent should not be problematic. On the contrary, if duodenal obstruction precedes the biliary stricture, the placement of a biliary stent is challenging, especially in type II bilioduodenal strictures. In a multicenter study, the success of biliary cannulation was assessed in 38 patients with indwelling duodenal stents. Most of the patients had type II bilioduodenal strictures. The technical success of biliary cannulation was only $34 \%$ in this study. ${ }^{25}$ In another study involving patients with previously placed duodenal stents, the success of biliary cannulation was lower with type II (76\%) than with type I (87\%) and III (100\%) strictures. ${ }^{10}$ Therefore, in cases at risk of developing obstructive jaundice such as those with dilated bile ducts and distal narrowing or biochemical cholestasis (raised gamma glutamyl transpeptidase and alkaline phosphatase), the placement of a biliary stent should be considered prior to duodenal stenting. ${ }^{25}$ In current practice, it may be reasonable to combine enteral stenting with EUS-BD in cases with failure of ERCP biliary cannulation. ${ }^{23,26}$

\section{EUS-guided biliary drainage}

With the recent advancements in therapeutic EUS, the management of MBOs has been revolutionized. EUS-BD has been shown to be safe and efficient in MBOs. ${ }^{27}$ EUS-BD is especially useful in cases where the papilla is not accessible due to duodenal invasion or in cases where biliary cannulation fails due to tumor infiltration of the papilla. ${ }^{26}$ Furthermore, in patients with an indwelling duodenal stent, EUS-BD may be superior to ERCP. ${ }^{28,29}$ Yamao et al. compared ERCP transpapillary stenting to EUS-BD in 39 patients with a duodenal stent in situ. ${ }^{29}$ The technical success of EUS-BD was significantly higher than ERCP ( $95.2 \%$ vs. $56 \%, p<0.01$ ). Notably, the difference in success was more significant when the duodenal stent overlapped the papilla (93.3\% vs. $22.2 \%, p<0.01) .{ }^{29}$ The main techniques of EUS-BD include EUS-guided choledochoduodenostomy (EUS-CDS), EUS-guided hepaticogastrostomy, and EUS-rendezvous techniques (Figs. 2, 3). EUS-guided hepaticogastrostomy is preferred when the duodenal bulb is involved due to tumor infiltration. Ogura et al. compared EUS-guided hepaticogastrostomy with EUS-CDS in patients with combined obstruction. ${ }^{30}$ The authors concluded that EUS-guided hepaticogastrostomy is better than EUS-CDS, with longer stent patency and fewer adverse events. ${ }^{30}$ There are no randomized trials comparing one approach to other and therefore, it may be premature to conclude the superiority 
Table 1. Studies Depicting the Outcomes of Endoscopic Management of Combined Biliary and Duodenal Obstruction

\begin{tabular}{|c|c|c|c|c|c|c|}
\hline Study & Number of patients & $\begin{array}{c}\text { Type of strictures } \\
\text { I/II/III }\end{array}$ & Technical success & $\begin{array}{l}\text { Median stent } \\
\text { patency }\end{array}$ & Survival & Re-intervention \\
\hline $\begin{array}{l}\text { Kaw et al. } \\
(2003)^{13}\end{array}$ & 18 & - & $94.4 \%$ & - & 78 days & 23.5 (11.7\% each) \\
\hline $\begin{array}{l}\text { Maire et al. } \\
(2006)^{14}\end{array}$ & $\begin{array}{c}100 \text { (23 combined } \\
\text { obstruction) }\end{array}$ & - & $91 \%$ & - & $11 \mathrm{mo}$ & $22 \%$ (biliary) \\
\hline $\begin{array}{l}\text { Mutignani et } \\
\text { al. }(2007)^{3}\end{array}$ & 64 & $31 / 25 / 8$ & $97 \%$ & - & $\begin{array}{l}81 \text { days (range, } \\
2-447 \text { days) }\end{array}$ & $19 \%$ \\
\hline $\begin{array}{l}\text { Moon et al. } \\
(2009)^{19}\end{array}$ & 8 & $3 / 5 / 0$ & $87.5 \%$ & - & 91 days & - \\
\hline $\begin{array}{l}\text { Katsinelos et } \\
\text { al. }(2010)^{12}\end{array}$ & 39 & $\begin{array}{l}\text { Sequential/simul- } \\
\text { taneous } 25 / 7\end{array}$ & $82.1 \%$ & $\begin{array}{l}\text { D-9 mo } \\
\text { B-3 mo }\end{array}$ & $9 \mathrm{mo}$ & $\begin{array}{c}28.1 \%(15.6 \% \\
\text {-duodenal, } 12.5 \% \\
\text { biliary) }\end{array}$ \\
\hline $\begin{array}{l}\text { Tonozuka et } \\
\text { al. }(2013)^{23}\end{array}$ & $\begin{array}{c}11 \\
\text { (EUS-BD-8, } \\
\text { ERCP-BD-3) }\end{array}$ & $1 / 10 / 0$ & $100 \%$ & $\begin{array}{l}\text { D-73.5 } \pm 69.7 \text { days } \\
\text { B-62.6 } \pm 60.4 \text { days }\end{array}$ & $76.5 \pm 67.8$ days & $\begin{array}{c}\mathrm{D}=0 \\
\mathrm{~B}=18.2 \%\end{array}$ \\
\hline $\begin{array}{l}\text { Canena et al. } \\
(2014)^{24}\end{array}$ & 50 & $35 / 11 / 4$ & $100 \%$ & $\begin{array}{l}\text { D-34 weeks } \\
\text { B-27 weeks }\end{array}$ & 18 weeks & $40 \%$ \\
\hline $\begin{array}{l}\text { Khashab et al. } \\
(2014)^{25}\end{array}$ & $\begin{array}{l}38 \\
\text { (previous duodenal } \\
\text { stent in place) }\end{array}$ & $\begin{array}{c}\text { 6/19/2 } \\
\text { (unclassified 11) }\end{array}$ & $34.2 \%$ & $\begin{array}{l}8 \text { patients died: } \\
151 \text { days }(35-530) \\
3 \text { patients alive: } \\
64 \text { days }(33-121)\end{array}$ & - & 8.3\% (biliary) \\
\hline $\begin{array}{l}\text { Hamada et al. } \\
(2018)^{2}\end{array}$ & $\begin{array}{c}110 \\
(\text { ERCP-90, } \\
\text { EUS-BD-20) }\end{array}$ & $45 / 46 / 19$ & - & $\begin{array}{l}\text { B-450 days } \\
\text { D-617 days }\end{array}$ & - & - \\
\hline $\begin{array}{l}\text { Staub et al. } \\
(2018)^{10}\end{array}$ & $\begin{array}{l}71 \text { (previous duodenal } \\
\text { stent in place) }\end{array}$ & $46 / 21 / 4$ & $\begin{array}{c}85 \% \\
87 \% / 76 \% / 100 \%\end{array}$ & - & 4.6 mo (mean) & - \\
\hline
\end{tabular}

D, duodenal; B, biliary; EUS-BD, endoscopic ultrasound-guided biliary drainage; ERCP, endoscopic retrograde cholangiopancreaticography.
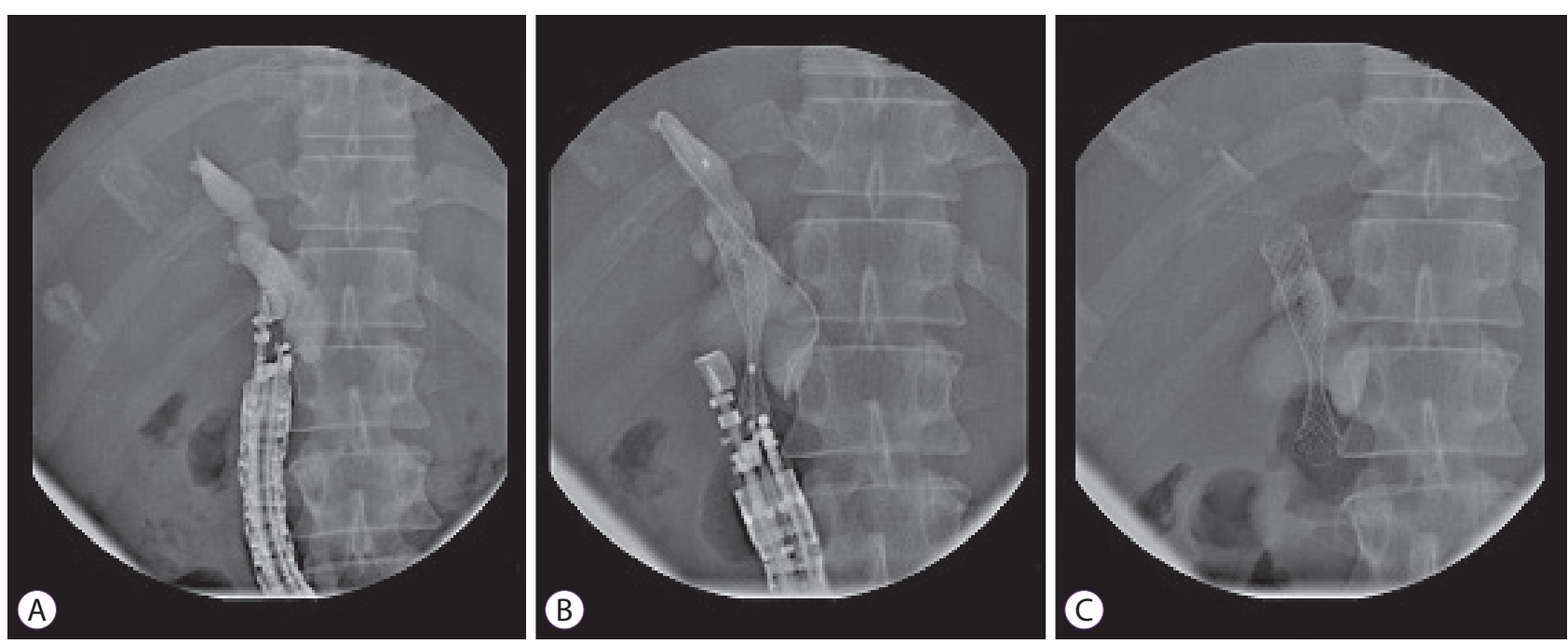

Fig. 2. Endoscopic ultrasound-guided choledochoduodenostomy. (A) Puncture of bile duct with a $19 \mathrm{G}$ needle and contrast injection, (B) placement of guidewire and initiation of stent deployment, $(\mathrm{C})$ complete deployment of choledochoduodenal stent.

of any one EUS approach. Early data indicates that the safety and efficacy of EUS-BD is comparable to ERCP. Presently, it is debatable whether EUS should be used as a primary modality for biliary drainage. Both modalities were comparable 

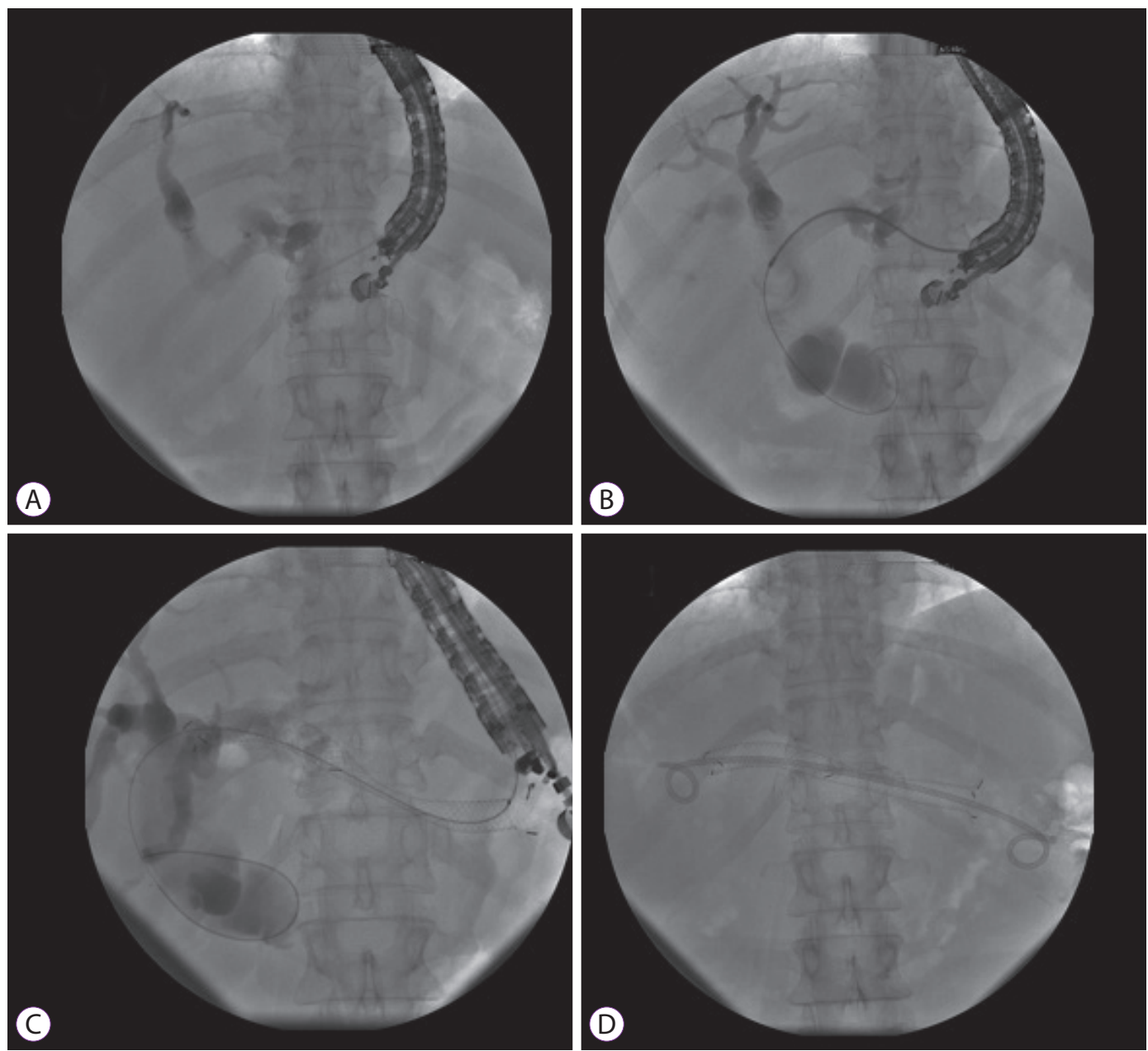

Fig. 3. Endoscopic ultrasound-guided hepaticogastrostomy. (A) Puncture of intrahepatic bile duct with a $19 \mathrm{G}$ needle, (B) placement of guidewire and dilatation of the tract with a catheter, $(C)$ and $(D)$. deployment of metal stent (note: a double pigtail plastic stent has also been placed within the metal stent).

in terms of success and rate of adverse events in two recent randomized trials. 31,32

\section{EUS-guided gastroenterostomy}

More recently, EUS-GE has been utilized for the management of malignant GOO. The advantage of EUS-GE over endoscopic stenting is that the site of intervention is away from the tumor site. Therefore, the problem of re-occlusion of the stent as a result of tumor overgrowth or ingrowth is unlikely as compared to endoscopic enteral stenting. ${ }^{33}$ In a recent study, EUS-GE was found to have similar efficacy to endoscopic stenting ( $83.3 \%$ vs. $67.3 \%)$. However, the recurrences and requirement of re-interventions were significantly lower in the EUS-GE group ( $4 \%$ vs. $28.6 \%$ ). ${ }^{33}$ EUS-GE has also been compared to surgical GE. ${ }^{34,35}$ In a recent multicenter study, EUS-GE and surgical GE had comparable clinical success ( $87 \%$ vs. $90 \%$ ), adverse events ( $16 \%$ vs. $25 \%$ ), and recurrent GOO (3\% vs. $14 \%) .{ }^{35}$ In another study, the adverse events were significantly lower in the EUS-GE group than in the laparoscopic GE group (12\% vs. $41 \%){ }^{34}$ Whether EUS-GE should be preferred to enteral stenting in patients with longer life expectancy ( $>2-4$ months) is debatable and randomized trials are warranted.

The technique of EUS-GE has evolved over last few years. Broadly speaking, EUS-GE can be performed either via a direct puncture technique or balloon-assisted technique. In both the techniques, the jejunum is filled with a large volume of water to enhance endosonographic visualization as well as co-localization of the jejunal loop to the stomach. The subsequent steps include transgastric puncture of the jejunum with needle, placement of the guidewire, balloon dilatation of the tract, and finally placement of a lumen-apposing metal stent. With the availability of electrocautery-enhanced lumen-apposing stents, the above-mentioned steps can be bypassed and stent deployment can be accomplished as a single step. ${ }^{36}$ 


\section{FUTURE PERSPECTIVES}

Combined endoscopic stenting for bilioduodenal strictures has been shown to be safe and effective. With improvement in chemotherapeutic regimens, the survival has increased and is likely to increase further in these patients. ${ }^{37}$ This means that the requirement of re-interventions may rise in future. Palliative modalities should be carefully chosen and tailored to the stage of disease, performance status, availability of different palliative options, and the patients' preferences. ${ }^{38}$ For example, in patients with longer life expectancy (>2-4 months), surgical gastrojejunostomy still holds promise and is associated with better long-term outcomes than endoscopic stenting for palliation of malignant GOO. ${ }^{39}$ As new modalities emerge, the ultimate aim would be to reduce the requirement of re-interventions and improve the quality of life in these patients.

The emergence of EUS as a therapeutic modality in both $\mathrm{MBO}$ and GOO has expanded the armamentarium of minimally invasive alternatives in patients who require dual drainage. In patients with an indwelling duodenal stent, EUS$\mathrm{BD}$ can be used as an alternative to ERCP. EUS can also be a potential first-line therapy for both biliary and duodenal strictures. ${ }^{40}$ However, the current evidence is from small studies with relatively short follow-up duration. In addition, these procedures have been performed by experts and may not reflect real-world practice. The technique of EUS-BD/EUS-GE is yet to be standardized, and dedicated accessories need to be developed for advanced EUS-guided drainage procedures. Therefore, at present, EUS-guided drainage may be utilized in cases of failed endoscopic biliary or duodenal stenting, where

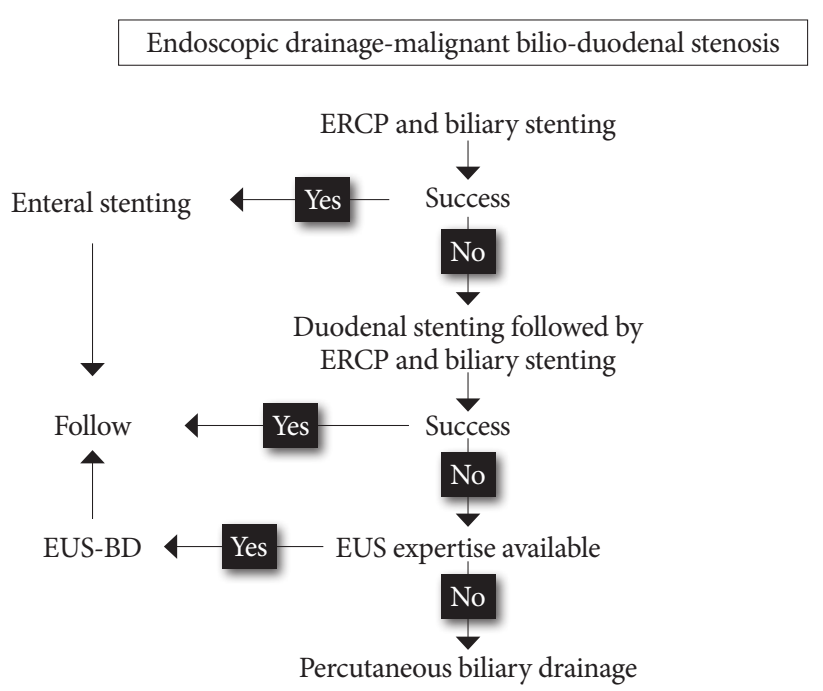

Fig. 4. Algorithmic approach to combined biliary and duodenal obstructions. ERCP, endoscopic retrograde cholangiopancreatography; EUS-BD, endoscopic ultrasound-guided biliary drainage. expertise is available (Fig. 4).

In future, various endoscopic approaches like ERCP and EUS-guided bilioduodenal bypass need to be compared in a randomized fashion.

\section{CONCLUSIONS}

Endoscopic management of bilioduodenal strictures is safe and effective in over $90 \%$ of cases. In terms of quality of life, morbidity, and cost of the procedure, endoscopic palliation is superior to surgical bypass. In cases with failure of ERCP, percutaneous or EUS-assisted drainage procedures are effective minimally invasive alternatives. The current body of evidence favors EUS-BD over percutaneous drainage. However, standardization of techniques and development of dedicated accessories are warranted for EUS-assisted procedures and therefore, percutaneous biliary drainage remains a valuable option in centers where expertise in therapeutic EUS is a constraint.

\section{Conflicts of interest}

The authors have no financial conflicts of interest.

\section{REFERENCES}

1. Van Heek NT, De Castro SM, van Eijck CH, et al. The need for a prophylactic gastrojejunostomy for unresectable periampullary cancer: a prospective randomized multicenter trial with special focus on assessment of quality of life. Ann Surg 2003;238:894-902; discussion 902-905.

2. Hamada T, Nakai Y, Lau JY, et al. International study of endoscopic management of distal malignant biliary obstruction combined with duodenal obstruction. Scand J Gastroenterol 2018;53:46-55.

3. Mutignani M, Tringali A, Shah SG, et al. Combined endoscopic stent insertion in malignant biliary and duodenal obstruction. Endoscopy 2007;39:440-447.

4. Hosono S, Ohtani H, Arimoto Y, Kanamiya Y. Endoscopic stenting versus surgical gastroenterostomy for palliation of malignant gastroduodenal obstruction: a meta-analysis. J Gastroenterol 2007;42:283-290.

5. Rudolph HU, Post S, Schlüter M, Seitz U, Soehendra N, Kähler G. Malignant gastroduodenal obstruction: retrospective comparison of endoscopic and surgical palliative therapy. Scand J Gastroenterol 2011;46:583590.

6. Zheng B, Wang X, Ma B, Tian J, Jiang L, Yang K. Endoscopic stenting versus gastrojejunostomy for palliation of malignant gastric outlet obstruction. Dig Endosc 2012;24:71-78.

7. Johnsson E, Thune A, Liedman B. Palliation of malignant gastroduodenal obstruction with open surgical bypass or endoscopic stenting: clinical outcome and health economic evaluation. World J Surg 2004;28:812817.

8. Siddiqui A, Spechler SJ, Huerta S. Surgical bypass versus endoscopic stenting for malignant gastroduodenal obstruction: a decision analysis. Dig Dis Sci 2007;52:276-281.

9. Inamdar S, Slattery E, Bhalla R, Sejpal DV, Trindade AJ. Comparison of adverse events for endoscopic vs percutaneous biliary drainage in the treatment of malignant biliary tract obstruction in an inpatient national 
cohort. JAMA Oncol 2016;2:112-117.

10. Staub J, Siddiqui A, Taylor LJ, Loren D, Kowalski T, Adler DG. ERCP performed through previously placed duodenal stents: a multicenter retrospective study of outcomes and adverse events. Gastrointest Endosc 2018;87:1499-1504.

11. Yao JF, Zhang L, Wu H. Analysis of high risk factors for endoscopic retrograde cholangiopancreatography biliary metallic stenting after malignant duodenal stricture SEMS implantation. J Biol Regul Homeost Agents 2016;30:743-748.

12. Katsinelos P, Kountouras J, Germanidis G, et al. Sequential or simultaneous placement of self-expandable metallic stents for palliation of malignant biliary and duodenal obstruction due to unresectable pancreatic head carcinoma. Surg Laparosc Endosc Percutan Tech 2010;20:410-415.

13. Kaw M, Singh S, Gagneja H. Clinical outcome of simultaneous self-expandable metal stents for palliation of malignant biliary and duodenal obstruction. Surg Endosc 2003;17:457-461.

14. Maire F, Hammel P, Ponsot P, et al. Long-term outcome of biliary and duodenal stents in palliative treatment of patients with unresectable adenocarcinoma of the head of pancreas. Am J Gastroenterol 2006;101:735-742.

15. Kikuyama M, Itoi T, Sasada Y, Sofuni A, Ota Y, Itokawa F. Large-balloon technique for one-step endoscopic biliary stenting in patients with an inaccessible major papilla owing to difficult duodenal stricture (with video). Gastrointest Endosc 2009;70:568-572.

16. Donatelli G, Cereatti F, Dumont JL, et al. Temporary duodenal stenting as a bridge to ERCP for inaccessible papilla due to duodenal obstruction: a retrospective study. Endosc Int Open 2016;4:E957-E963.

17. Goutorbe F, Rouquette O, Mulliez A, et al. Temporary placement of a covered duodenal stent can avoid riskier anterograde biliary drainage when ERCP for obstructive jaundice fails due to duodenal invasion. Surg Endosc 2017;31:625-631.

18. Topazian M, Baron TH. Endoscopic fenestration of duodenal stents using argon plasma to facilitate ERCP. Gastrointest Endosc 2009;69:166169.

19. Moon JH, Choi HJ, Ko BM, et al. Combined endoscopic stent-instent placement for malignant biliary and duodenal obstruction by using a new duodenal metal stent (with videos). Gastrointest Endosc 2009;70:772-777.

20. Tyberg A, Kumta N, Karia K, Zerbo S, Sharaiha RZ, Kahaleh M. EUS-guided gastrojejunostomy after failed enteral stenting. Gastrointest Endosc 2015;81:1011-1012.

21. Lee TH, Choi JH, Park do H, et al. Similar efficacies of endoscopic ultrasound-guided transmural and percutaneous drainage for malignant distal biliary obstruction. Clin Gastroenterol Hepatol 2016;14:1011-1019. e3.

22. Sharaiha RZ, Khan MA, Kamal F, et al. Efficacy and safety of EUS-guided biliary drainage in comparison with percutaneous biliary drainage when ERCP fails: a systematic review and meta-analysis. Gastrointest Endosc 2017;85:904-914.

23. Tonozuka R, Itoi T, Sofuni A, Itokawa F, Moriyasu F. Endoscopic double stenting for the treatment of malignant biliary and duodenal obstruction due to pancreatic cancer. Dig Endosc 2013;25 Suppl 2:100-108.

24. Canena J, Coimbra J, Carvalho D, et al. Endoscopic bilio-duodenal bypass: outcomes of primary and revision efficacy of combined metal- lic stents in malignant duodenal and biliary obstructions. Dig Dis Sci 2014;59:2779-2789.

25. Khashab MA, Valeshabad AK, Leung W, et al. Multicenter experience with performance of ERCP in patients with an indwelling duodenal stent. Endoscopy 2014;46:252-255.

26. Khashab MA, Fujii LL, Baron TH, et al. EUS-guided biliary drainage for patients with malignant biliary obstruction with an indwelling duodenal stent (with videos). Gastrointest Endosc 2012;76:209-213.

27. Wang K, Zhu J, Xing L, Wang Y, Jin Z, Li Z. Assessment of efficacy and safety of EUS-guided biliary drainage: a systematic review. Gastrointest Endosc 2016;83:1218-1227.

28. Hamada T, Isayama H, Nakai $Y$, et al. Transmural biliary drainage can be an alternative to transpapillary drainage in patients with an indwelling duodenal stent. Dig Dis Sci 2014;59:1931-1938.

29. Yamao K, Kitano M, Takenaka M, et al. Outcomes of endoscopic biliary drainage in pancreatic cancer patients with an indwelling gastroduodenal stent: a multicenter cohort study in West Japan. Gastrointest Endosc 2018;88:66-75.e2.

30. Ogura T, Chiba Y, Masuda D, et al. Comparison of the clinical impact of endoscopic ultrasound-guided choledochoduodenostomy and hepaticogastrostomy for bile duct obstruction with duodenal obstruction. Endoscopy 2016;48:156-163.

31. Park JK, Woo YS, Noh DH, et al. Efficacy of EUS-guided and ERCP-guided biliary drainage for malignant biliary obstruction: prospective randomized controlled study. Gastrointest Endosc 2018;88:277-282.

32. Bang JY, Navaneethan U, Hasan M, Hawes R, Varadarajulu S. Stent placement by EUS or ERCP for primary biliary decompression in pancreatic cancer: a randomized trial (with videos). Gastrointest Endosc 2018;88:9-17.

33. Chen YI, Itoi T, Baron TH, et al. EUS-guided gastroenterostomy is comparable to enteral stenting with fewer re-interventions in malignant gastric outlet obstruction. Surg Endosc 2017;31:2946-2952.

34. Perez-Miranda M, Tyberg A, Poletto D, et al. EUS-guided gastrojejunostomy versus laparoscopic gastrojejunostomy: an international collaborative study. J Clin Gastroenterol 2017;51:896-899.

35. Khashab MA, Bukhari M, Baron TH, et al. International multicenter comparative trial of endoscopic ultrasonography-guided gastroenterostomy versus surgical gastrojejunostomy for the treatment of malignant gastric outlet obstruction. Endosc Int Open 2017;5:E275-E281.

36. Amin S, Sethi A. Endoscopic ultrasound-guided gastrojejunostomy. Gastrointest Endosc Clin N Am 2017;27:707-713.

37. Nakai Y, Hamada T, Isayama H, Itoi T, Koike K. Endoscopic management of combined malignant biliary and gastric outlet obstruction. Dig Endosc 2017;29:16-25.

38. Perone JA, Riall TS, Olino K. Palliative care for pancreatic and periampullary cancer. Surg Clin North Am 2016;96:1415-1430.

39. Jeurnink SM, Steyerberg EW, van Hooft JE, et al. Surgical gastrojejunostomy or endoscopic stent placement for the palliation of malignant gastric outlet obstruction (SUSTENT study): a multicenter randomized trial. Gastrointest Endosc 2010;71:490-499.

40. Nakai Y, Isayama H, Yamamoto N, et al. Indications for endoscopic ultrasonography (EUS)-guided biliary intervention: does EUS always come after failed endoscopic retrograde cholangiopancreatography? Dig Endosc 2017;29:218-225. 